\title{
REAÇÕES EMOCIONAIS DOS PORTADORES DE DOENCAS SEXUALMENTE TRANSMISSÍVEIS NO MOMENTO DA CONFIRMAÇÃO DO SEU DIAGNÓSTICO.
}

\author{
Maria Helena Pessini de Oliveira* \\ Edna Paciência Vietta** \\ Tokico Murakaiva Moriya** \\ Elucir Gir***
}

\begin{abstract}
RESUMO. São levantadas as reações emocionais dos doentes portadores de doenças sexualmente transmissíveis (D.S.T.) que buscam assistência especializada. Foram entrevistados 20 pacientes, independente do sexo, idade, estado civil, condições sociais econômicas e especificação da doença, utilizando como instrumento a análise qualitativa dos depoimentos registrados destes indivíduos, mediante a questão: - Como você se sentiu ao saber portador de um D.S.T.? Conclui-se que os portadores de D.S.T., se enquandram como população de alto risco com relação às alterações emocionais sendo que, seus sintomas, sentimentos e/ou emoções refletem o medo quando ameaçados pela confirmação de serem portadores de D.S.T.
\end{abstract}

\begin{abstract}
Through their contact with subjects with sexually transmissible diseases (STD), the authors surveyed the emotional reactions of patients seeking specialized care. Twenty patients were interviewed regardless of sex, age, marital status, socioeconomic level or specific type of disease, using as a tool qualitative analysis of the recorded statements of these individuals after they were asked: - How did you feel when you knew that you had STD? It was concluded that patients with STD are a high-risk population with respect to emotional alterations, with their symptoms, feelings and/or emotions reflecting their fear when faced by the impending threat of confirmation of being STD patients.
\end{abstract}

\section{INTRODUÇÃO}

As doenças venéreas ou como atualmente se denominam, doenças sexualmente transmissiveis (D.S.T.), são moléstias infecciosas e parasitárias adquiridas, sobretudo pelo contato sexual.

$\mathrm{Na}$ verdade, o termo doenças sexualmente transmissíveis se aplica a uma série de enfermidades causadas por microorganismos das mais variadas espécies que têm em comum o fato de serem frágeis demais para sobreviver em certas condições de clima e temperatura, encontrando no organismo humano um ambiente ideal para seu desenvolvimento. Transferindo-se de um para outro organismo, entretanto, eles não podem expor-se às condições ambientais, que os faria parecer, necessitando um contato íntimo entre as pessoas em superfícies úmidas. Assim, o contato responsável por esse tipo de contaminação é o ato sexual, não apenas através do coito, mas do sexo oral e sodomia, provocando nesses casos, infecções no reto e na garganta. Um outro tipo de contato possível é aquele em que as D.S.T. são transmitidas, da mãe ao filho, via placentária, durante o parto (BALDY, 1985; BELDA, 1984; MENDONÇA, 1985; SILVA \& LOUREIRO, 1981).

Os agentes infecciosos têm uma predileção especial pelos territórios genitais e peri-genitais em ambos os sexos. Assim sendo, essas regiões, e portanto, o ser humano passa a ser considerado o "habitat" natural desses agentes (MENDONÇA, 1985).

Por se tratar de moléstia de alta infecciosidade, a

\footnotetext{
* Professora Assistente da Escola de Enfermagem de Ribeirão Preto - USP - Departamento Materno Infantil e Saúde Pública.

** Professora Assistente Doutora da Escola de Enfermagem de Ribeirão Preto - USP.

*** Auxiliar de Ensino da Escola de Enfermagem de Ribeirão Preto - USP.
} 
promiscuidade sexual, a troca acentuada de parceiros, as baixas condições de vida, aliados à liberação sexual, o livre acesso aos anticoncepcionais, a falta de uma educação sexual, contribuem para a disseminação em larga escala destas doenças.

Embora não se tenha dados estatísticos fidedignos, sabe-se que as D.S.T. situam-se entre aquelas enfermidades cuja distribuição endêmica estão disseminadas por todos os continentes. A falta de comprovação estatística não nos impede, no entanto, de afirmar sua importância epidemiológica no camo da Saúde Pública (BALDY, 1985).

As doenças de transmissão essencialmente sexual ou seja, sífilis, gonorréia, cancro mole, linfogranuloma venéreo, são consideradas de interesse da Saúde Pública, não apenas pelo alto índice de morbidade que apresentam, sobretudo, pelos aspectos culturais que as envolvem e que contribuem decisivamente para a permanência na comunidade e pelos danos que acarretam (FERREIRA, 1982).

Estas doenças constituem graves problemas sanitários, decorrentes das manifestações patológicas da fase aguda e das complicações físicas, psicológicas e sociais comprometendo as pessoas portadoras dessas doenças, principalmente nos casos assintomáticos.

As D.S.T. carregam consigo um estigma histórico vinculado à prostituição, à marginalização, ainda que se tenha buscado mudanças de nomenclatura continuam percebidas como doença originária do pecado. Estes preconceitos e tabus advindos dos conceitos do passado, acarretam sérios problemas psico-sociais, levando os indivíduos portadores a ocultarem seu problema a fim de não serem identificados pela sociedade nem se tornarem alvo de curiosidade, escárnio ou rejeição popular. Tal receio, diga-se de passagem, tem sua razão de ser, na medida em que envolvem problemas de ordem ética e social, e como conseqüência, questões pessoais freqũentemente difíceis de serem enfrentados conquanto revelem intimidades.

Atualmente uma nova doença, AIDS, vem provocando uma onda especulativa muito grande que, destarte, dá lugar a algumas notícias infundadas e desconcertantes. Haja visto a repercussão alarmante envolvendo esta doença, ocupando grandes espaços nosjornais ou manchetes de revistas, noticiários de rádios $\mathrm{e}$ televisão, procurando explorar com muito sensacionalismo o comportamento dos homossexuais. Explodem os interesses da sociedade envolvendo osportadores de D.S.T. que passam a ter seu comportamento sexual como objeto de análise, apontados como vítimas das aberrações e do abuso do hábito sexual.

O surgimento da AIDS acentuou ainda mais a preocupação das autoridades sanitárias em relação às doenças sexualmente transmissíveis.

Os preconceitos de pudor e vergonha, que envolvem as D.S.T. embora atualmente atenuado, continuam existindo em nossos dias, dificultando o relacionamento médico-paciente e médico-familia do paciente. A discriminação das doenças sexualmente transmissíveis acabam gerando no indivíduo implicações comportamentais.

A revelação das D.S.T., reativa nos indivíduos portadores conflitos sentimentais profundos e complexos. Estes conflitos refletem os sentimentos de culpa por terem contraído a moléstia, embaraço, inibição e'constrangimento diante de tal situação.

A inibição e o constrangimento dificultam e, às vezes, até impedem a procura da adequada assistência médica limitando-se não raro ajuda para a solução do problema num balcão de farmácia onde acabam por serem atendidos, medicados por pessoas incompetentes, inescrupulosas, despreparados, colocando a vida desses doentes em sérios riscos (BESTANE, 1978, 1980). Acresce ainda o fato de tais procedimentos impedirem o avanço da investigação epidemiológica da doença.

Isto posto, nosso objetivo centralizou-se na identificação das reações manifestadas nos indivíduos portadores de D.S.T., no momento em que lhes é confirmado o seu diagnóstico.

\section{MATERIAL E MÉTODO}

A pesquisa foi realizada no serviço de D.S.T., do ambulatório de um Hospital Escola na cidade de Ribeirão Preto, Estado de São Paulo, através do atendimento especializado of erecido por esta instituição.

Trabalhou-se com 20 portadores de D.S.T., casos novos, independente do sexo, idade, estado civil, condições sócio-econômica e especificidade da doença que comparecem ao serviço, a partir de novembro de 1985. 0 tamanho da amostra foi definido como suficiente no momento, em que, durante as entrevistas as reações emocionais tornaram-se repetitivas entre os pacientes, indicando concordância entre as respostas apresentadas.

Para efetivação da pesquisa, trabalhou-se basicamente com a entrevista individual, utilizando-se como instrumento o registro de depoimento dos pacientes atendidos imediatamente, após a confirmação de sua doença frente à seguinte indagação: - Como você se sente ao saber portador de uma doença sexualmente transmissível?

\section{Procedimento}

0 ambulatório de D.S.T. do Hospital Escola de Ribeirão Preto, conta com um serviço integrado de assistência de enfermagem desenvolvido através da modalidade de pós consulta médica. Estes atendimentos incluem outras atividades de educação em saúde, investigação epidemiológica, orientação e esclarecimentos quanto à doença, seu agente etiológico, modo de transmissão, período de incubação, controle do trata- 
mento, profilaxia, controle e segmento dos comunicantes e importância dos retornos.

Os casos novos de pacientes com D.S.T., que compareceram á este ambulatório, após terem seus diagnósticos confirmados durante a consulta médica, foram encaminhados ao serviço de enfermagem para receberem $o$ atendimento de rotina conforme mencionado acima.

Durante e pós consulta introduzia-se a questão "como você se sentiu ao saber que é portador de uma doença sexualmente transmissivel?"'.

Este questionamento não teve somente o întuito de alcançar os objetivos propostos por esta pesquisa, mas também atuar junto aos pacientes proporcionando esclarecimentos, conscientização, orientação e apoio quanto ao momento vivenciado por eles.

Ao término de cada entrevista, depois de marcar retorno, o paciente era dispensado. Em seguida, procedia-se o registro dos dados da entrevista procurando relatar com precisão as respostas obtidas dos pacientes.

Com base no resultado destas entrevistas, realizouse uma análise qualitativa dos dados obtidos, o que nos permitiu perceber os sintomas, sentimentos e atitudes do paciente.

\section{RESULTADO E DISCUSSÃO}

A população estudada constou de 20 pacientes assim distribuídos: $65 \%$ do sexo masculino e $35 \%$ do sexo feminino, entre a faixa etária de 18 a 42 anos de idade, predominando $45 \%$ a idade de 20 a 30 anos. Quanto ao estado civil 50\% eram casados, $30 \%$ solteiros e os demais 20\% sem situação definida (Tabela 1 e 2).

Com relação aos diagnóstico esta população ficou assim distribuída: $75 \%$ sífilis, $20 \%$ gonorréia e $5 \%$ AIDS.

TABELA 1 - Distribuição da população estudada segundo idade e sexo.

\begin{tabular}{lcrrrrrr}
\hline & \multirow{2}{*}{ Sexo } & \multicolumn{2}{c}{ MASC. } & \multicolumn{2}{c}{ FEM. } & \multicolumn{2}{c}{ TOTAL } \\
Idade & & No & N & No & $\%$ & No & $\%$ \\
\hline Abaixo & 20 & 3 & 15,0 & 2 & 10,0 & 5 & 25,0 \\
$20 \longrightarrow$ & 30 & 5 & 25,0 & 4 & 20,0 & 9 & 45,0 \\
$30 \longrightarrow$ & 40 & 3 & 15,0 & 1 & 5,0 & 4 & 20,0 \\
Acima & 40 & 2 & 10,0 & 0 & 0,0 & 2 & 10,0 \\
\hline \multirow{2}{*}{ TOTA L } & & 13 & 65,0 & 7 & 35,0 & 20 & 100,0 \\
\hline
\end{tabular}

TABELA 2 - Distribuição da população estudada segundo a idade e estado civil.

\begin{tabular}{|c|c|c|c|c|c|c|c|c|}
\hline \multirow{2}{*}{$\begin{array}{r}\text { Estado } \\
\text { Civil } \\
\text { Idade }\end{array}$} & \multicolumn{2}{|c|}{ CASADO } & \multicolumn{2}{|c|}{ SOLTEIRO } & \multicolumn{2}{|c|}{ OUTROS } & \multicolumn{2}{|c|}{ TOTAL } \\
\hline & No & $\%$ & № & $\%$ & No & $\%$ & № & $\%$ \\
\hline Abaixo 20 & 2 & 10,0 & 2 & 10,0 & 1 & 5,0 & 5 & 25,0 \\
\hline $20 \longrightarrow 30$ & 3 & 15,0 & 4 & 20,0 & 2 & 10,0 & 9 & 45,0 \\
\hline $30 \longrightarrow 40$ & 3 & 15,0 & 0 & 0,0 & 1 & 5,0 & 4 & 20,0 \\
\hline Acima 40 & 2 & 10,0 & 0 & 0,0 & 0 & 0,0 & 2 & 10,0 \\
\hline TOTAL & 10 & 50,0 & 6 & 30,0 & 4 & 20,0 & 20 & 100,0 \\
\hline
\end{tabular}

Nos Quadros 1 e 2 apresentam-se as principais reações emocionais obtidas respectivamente dos pacientes entervistados.

QUADRO 1 - Sintomas, sentimentos e ou emoções e atitudes manifestadas pelos pacientes do D.S.T., no momento da confirmação de seu diagnóstico.

\begin{tabular}{|lll|}
\hline SINTOMAS & SENTIMENTOS E OU EMOÇÕES & ATITUDES \\
\hline Preocupação & Raiva do parceiro & Agressividade \\
Angústia & Desilusão com relação ao & Vingança \\
Ansiedade & Medos diversos & Rejeição \\
Dor e & Vergonha & Desprezo \\
desconforto & Sentimento de imoralidade & Negação \\
Desespero & Sento & Revolta \\
Tristeza e ou & Sentimento de culpa & \\
Depressão & Solidão & \\
& Pena & \\
\hline
\end{tabular}

O Quadro 1 nos revela ser esta, uma população de auto risco em termo de Saúde Mental, dado a constatação de vários sintomas de ordem emocional característica de crise acidental.

Crises são episódios que afetam o equilíbrio dos indivíduos, provocando tensões com conseqüentes modificações do estado físico, emocional e social. Estes episódios são temporários, ocorrem em fase de transição no desenvolvimento da personalidade ou quando o indivíduo enfrenta situações problemátics (MINZONI et alii, 1977).

As crises acidentais acontecem em decorrência de situações difíceis provocadas pelos chamados "azares da vida": acidentes ou desgraça: Dentre as situações quep odem levar a uma crise acidental, acreditamos 
poder incluir o momento da confirmação de um diagnóstico de D.S.T.

Segundo CAPLAN (1966), durante o período de crise, a pessoa torna-se mais vulnerável aos transtornos emocionais sendo, também, mais suscetível de receber ajuda. Sua resistência ao transtorno mental pode ser aumentada na medida em que aprende a ampliar seu repertório de habilidades efetivas, para a solução de seus problemas. Desse modo, é possível através da intervenção em crise, evitar a utilização de respostas regressivas, fora da realidade, ou socialmente não aceitas quando os indivíduos enfrentam situações desta natureza.

Os sintomas mais freqüentes, identificados na amostra foram: preocupação: relacionado com a ansiedade geralmente associaod aos acontecimentos posteriores, problemas a serem resolvidos no momento e situações a serem enfrentadas. Angústia: relacionado com o impacto frente ao inevitável, medo das conseqüências, sentimentos de culpa e de traição (tanto o de "ser" traidor, como o de "ser" traído), medo de ser rejeitado, medo de ser abandonado. Dor e desconforto: pelos sintomas físicos específicos da doença e provavelmente exacerbado pelo medo, pela ansiedade e tensão. Desespero: pela situação expressa em termos de uma desgraça, algo que não poderia acontecer, azar. Situação que envolve decisões difíceis de serem encaradas, principalmente pelo medo das conseqüências, reveladas através do medo da agressão, rejeição e abandono, agravados ainda pela angústia da presença de sintomas físicos, incõmodos, conotação de imoralidade ou desregramento. Tristeza e ou depressão: pela raiva, revolta, culpa e auto-punição. Tudo isto acrescido de sentimentos e ou emoções tais como desilusão e decepção com o parceiro (tanto o transmissor quanto o comunicante).

Todos estes sintomas e ou emoções estão estritamente relacionados e interdependentes, conseqüentes ou casais da própria situação vivencial do paciente, mediante a confirmação de seu diagnóstico.

Os sintomas identificados variam de intensidade, de acordo e sobretudo em relação ao sexo e ao estado civil, sendo mais intenso nas mulheres e nos pacientes casados ou que têm um parceiro fixo e de certo vínculo afetivo. Neste caso o paciente tem que enfrentar as reações quase sempre imprevisíveis de seus parceiros. Os sentimentos de raiva em relação ao panceiro que transmitiu a doença, gerou na quase totalidade dos pacientes da amostra, atitudes de agressividade como: "querer bater", "matar", "prejudicar", "vingar-se", manifestos através da rejeição, desprezo, negação do outro, pena e revolta. Alguns manifestaram sua revolta através do desejo de transmitir a doença a outras pessoas (vingança).

Uma outra constatação é a de que o paciente procure transferir ao parceiro que o contaminou toda culpa de sua doença. Torna-se incapaz de perceber e admitir o grau de sua participação.

Por outro lado o comunicante sente-se traído, desrespeitado, revoltado e agressivo embora as mulheres parecem aceitar com mais naturalidade, às vezes até com certo conformismo, porém com vergonha.

Durante as entrevistas não se constatou na amostra estudada, nenhuma atitude positiva no sentido de procurar ajudar o parceiro, revelando-o como portador de D.S.T., nem preocupação com o tratamento precoce dos possíveis comunicantes. As atitudes mais freqūentes com relação ao parceiro, é portanto, de agressão, de desprezo, de negação e de pena. Daí a dificuldade na obtenção da colaboração espontânea da revelação dos contatos e até mesmo a disponibilidade do portador em convocar ao serviço a presença do comunicante.

Estas dificuldades observadas são traduzidas como empecilhos para um atendimento eficaz de controle epidemiológico das D.S.T., uma vez que a detecção dospossíveis infectados é o instrumento básico para a interrupção da cadeia do processo infeccioso.

QUADRO 2 - Tipos de medos revelados pelos pacientes de D.S.T no momento da confirmação de seu diagnóstico.

- Medo de que os familiares descubram a sua doença

- Medo da reação do parceiro no momento

- Medo em não obter a cura total

- Medo da impotência sexual

- Medo da secreção uretral

- Medo de ser abandonado

- Medo da rejeição

- Medo da solidão

- Medo de morrer

- Medo de ser portador de AIDS

- Medo da reação das pessoas

0 Quadro 2 mostra-nos uma população num nível de tensão elevada dada aos medos que a situação envolve: $O$ medo de que os familiares descubram a sua doença, chega até mesmo ao desespero por receio de violência, desprezo e abandono. Isto se revela pela ignorância de que seu diagnóstico será mantido em sigilo. Alguns pacientes dizem se sentir "perdidos" ou "arrazados", caso isto venha acontecer. Medo da reação do parceiro no momento da revelação, a maioria não consegue sequer pensar como revelar o fato ao parceiro ou parceira. Outros têm medo da reação imprevisível que esta revelação possa causar, chegando mesmo a se negar efetuá-la. Medo em não obter cura total, esta, relacionada com tabus, preconceitos e desinformação ou até mesmo da "punição divina", revelado pelos pacientes que acreditam terem cometido pecado e portanto não merecem absolvição. Medo da impotência sexual, também relacionado com tabus, preconceitos, desinformações e falsos conceitos adquiridos em torno das D.S.T. como causadoras de impotência sexual, baseada na relação da perda da potência sexual, confundida com esterilidade que possam ocorrer em caso de 
gonorréias não tratadas. 0 sintoma da dor e o medo de contrair a doença novamente podem levar os indivíudos a retrair temporariamente, seus impulsos sexuais, criando com isso uma preocupação acentuada quanto à perda de potência sexual, observada mais nos indivíduos do sexo masculino que no sexo feminino. $M e$ do de ser abandonado, este sentimento foi constatado em todos os pacientes atendidos, manifestado pelo sentimento de solidão, de estar só e de ser rejeitado, desprezado pelo parceiro, de não merecer seu perdão, de não merecer confiança, respeito e consideração, sintomas estes bastante relacionado com a culpa e autopunição. Medo da rejeição, todos, sem exceção manifestaram a certeza de que seriam rejeitados, mostrando portanto o desejo de se isolar, "sumir por algum tempo" ou até mesmo "morrer". Medo da solidão, os pacientes sentem-se só ao mesmo tempo em que começam a manif estar o desejo de se isolar das demais pessoas ou se sentem tão diferentes dos outros, ' indignos", isolando-se, reforçando assim seu sentimento de abandono. Medo de morrer, estes sentimentos foram detectados em alguns casos pela manifestação verbal através da pergunta feita pelo paciente à enfermeira, sobre a gravidade da sua doença, "se tem cura" 'se morre muita gente desta doença", ou de não "agüentar a situação". No entanto nossa hipótese é de que tal sentimento esteja relacionado à auto-censura à culpa e à auto-punição e com o pecado. Medo de ser portador da AIDS, principalmente nos casos dos homossexuais este medo foi manifestado pelo interesse em saber quais os sintomas da AIDS, estar desconfiado do diagnóstico, pedir sinceridade quanto suas possibilidades de cura e de sobrevivência e até mesmo perguntar se era portador da AIDS. Medo da reação das pessoas, medo de que as pessoas descubram pelos sintomas ou pelo tratamento, medo de serem agredidos ou rejeitados pela sociedade.

E difícil para o paciente assumir as D.S.T., pois implica também, toda uma gama de reações geralmente manifestas por sentimentos de vergonha, raiva, medo, revolta, sentimentos de inferioridade etc. Tais reações devem ser identificadas e compreendidas, não só pela enfermagem, mas também, por todo o pessoal que lida com esta população, influenciam decisivamente no processo de tratamento desses pacientes, uma vez que neste momento são mais susceptíveis a receber ajuda.

A enfermeira deve estar atenta a tais alterações emocionais, que possam ocorrer com os portadores de D.S.T., no momento da confirmação diagnóstica, apoiando-o, compreendendo, esclarecendo-o quanto a situação vivencial, procurando eliminar falsos conceitos e tabus que ainda persistem com relação a esta moléstia.

\section{CONCLUSÕES}

Dos dados obtidos pudemos constatar que:

a) A amostra dada enquadra-se nas populações consideradas de alto risco em relação às perturbações emocionais, merecendo portanto atenção especial.

b) As enfermeiras como profissionais que vêm se destacando na assistência a esta população, assumem desta feita uma tarefa importante na prevenção, na cura e controle das D.S.T. e particularmente na situação vivencial de crise emocional desses pacientes.

c) 0 momento da confirmação diagnóstica se apresenta em acordo com o estudo, no momento desencadeado da situação de crise, quando estabelece os sintomas emocionais, sendo portanto o momento decisivo para intervenção e apoio.

d) As enfermeiras devem estar atentas aos aspectos emocionais que envolvem os pacientes de D.S.T., e é necessário buscar assessoria especializada para tal intervenção.

e) Os sintomas e emoções evidenciados na amostra, certamente interferem na cura, tratamento e no controle das D.S.T. na medida em que passam a determinar as atitudes deste paciente diante dos fatos.

f) Estas atitudes podem ser consideradas como um dos aspectos que interferem no avanço das investigações epidemiológicas das D.S.T., bem como para a prevenção e controle destas enfermidades.

\section{REFERÊNCIAS BIBLIOGRÁFICAS}

1. BALDY, J.L.S. Doenças infecciosas e parasitárias transmitidas por contato sexual: Aspectos epidemiológicos e de Saúde Pública. Revista Associação Médica Brasileira, São Paulo, 31(9/10): 146-51, set./out. 1985.

2. BELDA, W. Doenças de transmissão sexual. Ass. Bras. Derm., 3(59) 123-5, 1984.

3. BESTANE, W.J. A gonorréia e outras uretrites na cidade de Santos, Estado de São Paulo. Revista Associação Médica Brasileira, São Paulo, 24(4): 133-8, abr. 1978.

4. BESTANE, W.J. et alii. Alguns aspectos da prescrição de medicação para o tratamento de gonorréia em farmácias de Santos (SP). Revista Associação Médica Brasileira, São Paulo, 26(1): 1-3, jan. 1980.

5. CAPLAN, G. Princípios de psiquiatria preventiva. Buenos Aires, Paidós, 1966.

6. FERREIRA, J. Doenças sexualmente transmissíveis. Curso Nacional de Dermatologia Sanitária da Secretaria do Meio Ambiente. Porto Alegre, SSMA, 30 p., 1982. Mimeogr.

7. LEAVELL, H. \& CLARK, E.G. Medicina preventiva. São Paulo. MacGraw-Hill do Brasil, 1976.

8. MENDONÇA, J.S. Doenças venéreas ou doenças sexualmente transmissíveis. Revista Associação Médica Brasileira, São Paulo, 36(9/10): 144-6, set./out. 1985.

9. MINZONI, M.A.; ALENCASTRE, M.B.; GOULART, M.C.S.; PACIÊNCIA, E.; RODRIGUES, A.R.F.; SILVA, J.N.; CARSWELL, W.A.; SAEKIT, T. Enfermagem em saúde mental e psiquiatria: a busca de uma posição. Revista Enfermagem Novas Dimensões, São Paulo, 3(6): 350-5, nov./dez. 1977.

10. ORGANIZACION MUNDIAL DE LA SALUD. La Salud del adolescentes y el joven en las Américas. Washington, 1985. $335 \mathrm{p}$.

11. RUDIO, F.V. Orientação não diretiva: na educação, no aconselhamento e na psicoterapia. Rio de Janeiro, Petrópolis, Vozes, 1976.

12. SILVA, D. \& LOUREIRO, A. Doenças sexualmente transmissíveis (D.S.T.). Perfil histórico. Hiléia Médica, Belém, 3(1): 29-34, 1981. 